\title{
Welfare Effects of Social Cash Transfers in Chipata and Kazungula Districts of Zambia
}

\author{
Gelson Tembo (Corresponding author) \\ Department of Agricultural Economics, University of Zambia, Lusaka \\ P.O. Box 32379, Lusaka, Zambia \\ E-mail: tembogel@gmail.com
}

Bernadette Chimai

Department of Agricultural Economics

University of Zambia, Lusaka, Zambia

Nicholas Freeland

MASDAR International Consultants, Reading, UK

Brian P. Mulenga

Indaba Agricultural Policy Research Institute, Lusaka, Zambia

Received: January 10, 2013 Accepted: February 2, 2013

doi:10.5296/ber.v4i1.5532ＵRL: http://dx.doi.org/10.5296/ber.v4i1.5532

\begin{abstract}
This study uses the odds-weighted regression approach and data from two spatially separated social cash transfer (SCT) programs in Zambia to determine the impact of cash transfers on household welfare. The same analytical framework was also applied on sub-samples of poor and relatively less poor households, where the wealth ranking was done using an asset-based index derived through principal components analysis. The results confirm positive SCT effects on per capita consumption expenditure and that the sizes and relative significance of these effects vary by program design and by the household's asset wealth. The effects were especially unambiguously positive and significant for non-food consumption. While the impact on food expenditure was positive and significant in the rural Kazungula SCT program, the impact on
\end{abstract}


non-food per capita consumption expenditure was three times greater. In the urban scheme in Chipata, program impacts were only significant on non-food expenditure. Future intervention designs need to take into account such heterogeneity in level and shape of potential impacts if they are to be effective.

JEL codes: C14, C21, D63, I38.

Keywords: Social cash transfers, Consumption expenditure, Impact, Chipata, Kazungula, Zambia

\section{Introduction}

Zambia has been implementing social cash transfer (SCT) schemes since 2003 with the primary aim to reduce extreme poverty among the poorest households with insufficient or no labour capacity. From the maiden pilot scheme in Kalomo in 2003, SCT schemes have since spread to 18 more districts and preparations are under way to add another 31. Tembo et al. (2014) provide a more comprehensive overview of the evolution of SCTs in Zambia.

This study uses survey data from two structurally different and spatially separated pilot schemes in Chipata and Kazungula Districts of Zambia to determine the impact of SCTs on household welfare. To the best of our knowledge, this study is the first comprehensive treatment of the impact of SCTs for the two schemes. Recent SCT impact evaluation work in Zambia has focused on Kalomo, the oldest scheme (Tembo et al. 2014), and the more recent programs such as the Monze SCT scheme (Handa et al., 2012; Seidenfeld et al., 2011) and the Child Grant Program (CGP) (Handa et al., 2013a; Handa et al., 2013b; Daidone et al., 2013). No such study has been done on the Chipata and/or Kazungula pilot schemes, both of which were modelled after Kalomo with a 10 percent selection threshold and a purely community-based targeting system. However, neither the Kalomo scheme nor the CGP model is completely identical to the Chipata and/or Kazungula schemes. While the Chipata scheme is the first urban-based scheme and includes an explicit educational allowance, Kazungula represents sparsely populated, hard-to-reach rural areas (RHVP 2007). ${ }^{1}$ Following Tembo et al. (2014), we measure not only aggregate effects but also heterogeneous impact across household wealth strata.

We use Hirano, Imbens and Ridder's (2003) flexible and fully efficient odds-weighted regression approach to estimate aggregate and heterogeneous impact on household consumption. Heterogeneous impact was estimated across wealth categories, where an asset-based index generated through principal components analysis (PCA) (Filmer and Pritchett 2001) was used as the stratifying variable. The results indicate significant positive aggregate effects on household welfare in both pilot districts. The impact was especially large with respect to non-food expenditure, regardless of the household's wealth status. Food expenditure effects were unambiguously positive and significant only in the rural scheme while in the urban-based scheme of Chipata such effects were positive and significant only among asset-poor households.

\footnotetext{
1 The two schemes under study had been running for at least two years by the time of the surveys.
} 
In the rest of the paper we first present the analytical framework in section 2. Sections 3 and 4 present methods and procedures, and results, respectively. Summary and conclusions are presented in section 5 .

\section{Analytical Framework}

\subsection{Conceptual Arguments for Cash Transfers}

SCTs are motivated by extreme liquidity constraints that households experience during less productive stages in their life-cycle, during income shocks and situations of extreme poverty. These liquidity constraints are exacerbated by inherently imperfect credit markets (Gertler, Martinez, \& Rubio-Codina, 2006). Cash transfers can smoothen consumption and ensure that households do not fall below a critical threshold that is necessary to make a 'decent' living. One of the most reliable measures of welfare in the literature is consumption expenditure. Although expenditure and income are supposed to be equivalent, the latter tends to be volatile and prone to under-reporting bias.

Program effects on consumption may not be homogeneous across beneficiary households due to variations in initial wealth levels. Relatively less poor households may have the relevant preconditions to use the SCTs to attain some of the outcomes quicker than their poorer counterparts. Conversely, poorer households may have had very low consumption levels to start with, leading to huge effects of the SCTs. Differences in the setting (rural-urban; remote-near cities) and other design elements may also foster heterogeneous impact.

\subsection{Data and Data Sources}

This study uses two cross-sectional data sets from three independent surveys conducted in 2007 by CARE International. In the first stage, Community Welfare Assistance Committees (CWAC) (the primary sampling units) were selected through probability proportional to size (PPS). After this, SCT beneficiary households and households not receiving but with similar characteristics as beneficiaries were selected using simple random sampling. ${ }^{2}$ Comparison households were selected from among households that had qualified to be in the program based on the selection criteria but were left out only on account of the 10 percent cut-off point. Each of the two studies had a sample size of 200 households. ${ }^{3}$ About $46-53$ percent of the households were SCT beneficiaries.

\subsection{Impact Estimation}

In the odds-weighted regression framework (Hirano, Imbens and Ridder 2003), impact is the estimated slope coefficient $\hat{\beta}_{1}$ in the weighted-regression model

\footnotetext{
${ }^{2}$ CWACs and Area Coordinating Committees (ACCs) are the grassroots structures of the Public Welfare Assistance Scheme (PWAS), which is a national scheme responsible for coordinating all social welfare interventions down to the community levels. As geographic units, the CWACs are used to define specific areas with a certain number of villages, and in turn the CWACs are nested within ACCs.

${ }^{3}$ See Tembo and Freeland (2008) for details about the two surveys.
} 


$$
\ln (y)=\beta_{0}+\beta_{1} w+e
$$

where the observations are weighted by 1 for treatment households and by the odds-ratio, $\hat{P}(\mathbf{x}) /(1-\hat{P}(\mathbf{x}))$, for comparison households; $\beta_{0}$ and $\beta_{1}$ are parameters to be estimated; and $e$ is a zero-mean error term. The dependent variable, $\ln (y)$, is the natural logarithm of per capita consumption expenditure on food, non-food or both. $\hat{P}(\mathbf{x})=E(w=1 \mid \mathbf{x})$ is the conditional probability of participation estimated as;

$$
\operatorname{Pr}(w=1 \mid \mathbf{x})=\Phi\left(\alpha+\boldsymbol{\delta}^{\prime} \mathbf{x}+\varepsilon\right)
$$

where $w$ is a dichotomous variable equal to one if the household is an SCT beneficiary and zero otherwise, $\Phi$ is a standard normal cumulative distribution function (CDF), $\varepsilon$ is the error term; $\alpha$ and $\boldsymbol{\delta}$ are parameter and vector of parameters to be estimated; and $\mathbf{x}$ is a vector of household and community covariates used in the beneficiary selection process. Only variables that were found to be correlated with the outcome variable were included in $\mathbf{x}$ (Caliendo and Kopeinig, 2008). Equation (2) was estimated using maximum likelihood in Stata (StataCorp 2008) for both Chipata and Kazungula (estimation results not reported). Before the predicted probabilities from equation (2) could be used in the computation of the odds ratios, care was taken to ensure the balancing and common support properties were satisfied (Rosenbaum and Rubin 1985; Caliendo and Kopeinig 2008; Jalan and Ravallion 2003; Cameron and Trivedi 2005; Becker and Ichino 2002; Leuven and Sianesi 2003; Tembo et al. 2014).

In addition to equation (1), we also use the odds-weighted regression framework to estimate impact disaggregated by poverty status:

$$
\ln (y)=\gamma_{0}+\gamma_{1} w+\gamma_{2} w * D+u
$$

where $D$ is a dummy variable equal to 1 if the household was categorized as asset poor (falling in the bottom two quintiles of the PCA-based wealth index) and zero otherwise; $\gamma_{0}, \gamma_{1}$, and $\gamma_{2}$ are parameters to be estimated; and $u$ is a zero-mean error term. As in Equation (1), the observations were weighted by 1 for treatment households and by $\hat{P}(\mathbf{x}) /(1-\hat{P}(\mathbf{x}))$ for comparison households. Based on (3), the estimated impact is equal to $\hat{\gamma}_{1}$ if the household falls in the less poor category $(D=0)$ and $\hat{\gamma}_{1}+\hat{\gamma}_{2}$ otherwise $(D=1)$. 


\section{IIl Macrothink}

\section{Results and Discussion}

\subsection{Descriptive statistics}

The descriptive results confirm that the SCT target population is extremely poor, characterized by elderly heads, high dependency ratios, and high incidences of female- and widow-headed households (Table 1). More than half the children 0-16 years old are orphaned. Of the two schemes under study, the urban-based Chipata scheme has the highest incidences of orphan-hood, and female- and widow-headed households.

Table 1. Selected characteristics of SCT target populations in Chipata and Kazungula

\begin{tabular}{|c|c|c|}
\hline & \multicolumn{2}{|c|}{ District/scheme } \\
\hline Variable & Chipata & Kazungula \\
\hline Sample size & 200 & 200 \\
\hline Number of meals by children per day & 2.4 & 1.5 \\
\hline Household income ('000 ZMK) & 979.0 & 366.6 \\
\hline Age of the household head (years) & 55.4 & 61.9 \\
\hline Widow-headed households (\%) & 65.0 & 55.0 \\
\hline Male-headed households (\%) & 28.0 & 31.0 \\
\hline Orphanhood (\%) & 78.0 & 44.0 \\
\hline Effectively active members (\%) & 19.3 & 15.2 \\
\hline
\end{tabular}

Kazungula had the oldest household heads (averaging 62 years), highest dependency ratios, and the lowest numbers of meals eaten by children (1.5 per day, compared to about 2.4 meals per day in Chipata). Eligible households in Kazungula also cultivate a smaller land area of about 0.3 hectares, and have the lower non-SCT income levels per household, averaging ZMK366,600 (US\$93) per annum, compared with ZMK979,000 (US\$245) in Chipata. 
Table 2. Probit results for the propensity score models for Chipata and Kazungula SCT programs

\begin{tabular}{|c|c|c|c|c|c|c|}
\hline \multirow[b]{2}{*}{ Variable } & \multirow[b]{2}{*}{ Variable description } & \multicolumn{3}{|c|}{ Chipata } & \multicolumn{2}{|c|}{ Kazungula } \\
\hline & & Marginal ef & ffect & Standard errol & Marginal effec & Standard erro \\
\hline & & (1) & & (2) & (3) & (4) \\
\hline hsex & Sex of head, $1=$ male & -0.0616 & & 0.4797 & 0.1004 & 0.4226 \\
\hline dhse & Household owns a house, $1=$ yes & 0.0695 & & 0.2261 & -0.0852 & 0.2395 \\
\hline dhdold & Head 60 years or older,1=yes & 0.1002 & & 0.5548 & $-0.3905 *$ & 0.5391 \\
\hline hage & Age of household head (years) & -0.0383 & $*$ & 0.0568 & 0.0083 & 0.0143 \\
\hline hag2 & Age-squared & 0.0003 & $*$ & 0.0005 & - & - \\
\hline dfprim & Girls in primary school,1=yes & -0.0342 & & 0.2679 & -0.1702 & 0.2909 \\
\hline dfsec & Girls in secondary school,1=yes & 0.2825 & $* *$ & 0.3332 & -0.2068 & 0.4994 \\
\hline dmprim & Boys in primary school,1=yes & 0.3552 & $* * *$ & 0.3031 & 0.0799 & 0.3176 \\
\hline dmsec & Boys in secondary school, $1=$ yes & 0.4114 & $* * *$ & 0.3519 & $0.2737 *$ & 0.4509 \\
\hline dwido & Marital status, $1=$ widowed & -0.0052 & & 0.8249 & $0.4866 *$ & 0.6969 \\
\hline deprat & Dependency ratio & 0.0198 & & 0.0558 & 0.0022 & 0.0324 \\
\hline c0to14 & Children 14 years or younger & -0.0465 & & 0.1091 & -0.0245 & 0.1227 \\
\hline m15to30 & Male members $15-30$ years & 0.0030 & & 0.1346 & $-0.1513 *$ & 0.2169 \\
\hline f15to30 & Female members $15-30$ years & 0.0363 & & 0.1506 & 0.0297 & 0.2165 \\
\hline m31to45 & Male members $31-45$ years & 0.0780 & & 0.3111 & $-0.3346 *$ & 0.4783 \\
\hline f31to45 & Female members $31-45$ years & -0.0422 & & 0.2940 & 0.1970 & 0.3813 \\
\hline m46to60 & Male members $46-60$ years & 0.1560 & & 0.5131 & -0.0123 & 0.5369 \\
\hline f46to60 & Female members $46-60$ years & -0.1064 & & 0.3669 & $-0.2967 *$ & 0.3673 \\
\hline m61plus & Members 61 years or older & -0.0973 & & 0.3073 & 0.1819 & 0.3191 \\
\hline dove & Household with orphans, $1=$ yes & 0.1577 & & 0.4852 & -0.0693 & 0.5250 \\
\hline wj & Asset wealth index & - & & - & 0.0053 & 0.0258 \\
\hline \multicolumn{7}{|c|}{ Interaction terms $^{a}$} \\
\hline hsex x wj & & $-5.2 \times 10^{-6}$ & & 0.0276 & -0.0046 & 0.0318 \\
\hline dwido $\mathrm{x} \mathrm{u}$ & & 0.0080 & & 0.0236 & $-0.0193 *$ & 0.0232 \\
\hline dove $x$ wj & & -0.0167 & $*$ & 0.0231 & -0.0051 & 0.0250 \\
\hline hsex x do & $\mathrm{vc} x \mathrm{wj}$ & & & & 0.0242 & 0.0468 \\
\hline hsex x du & & -0.5968 & $* * *$ & 0.7383 & 0.0720 & 0.6358 \\
\hline dwido $\mathrm{x} \mathrm{c}$ & Oto14 & 0.0418 & & 0.1353 & 0.0708 & 0.1700 \\
\hline dwido $\mathrm{x} \mathrm{n}$ & 61plus & -0.0596 & & 0.3422 & -0.0825 & 0.3904 \\
\hline dwido $\mathrm{x} \mathrm{d}$ & & -0.1984 & & 0.6728 & -0.1318 & 0.6092 \\
\hline dwido $\mathrm{x} \mathrm{d}$ & eprat & 0.0295 & & 0.0541 & $-0.0264 *$ & 0.0398 \\
\hline deprat $\mathrm{x} \mathrm{c}$ & ovc & -0.0173 & & 0.0538 & - & - \\
\hline dove $\mathrm{x}$ de & prat & - & & - & 0.0183 & 0.0399 \\
\hline hsex x du & ido $\mathrm{x}$ dove & 0.6338 & $* * *$ & 0.4401 & -0.3960 & 1.1767 \\
\hline Joint signi & ficance of regions/ACCs & 0.0100 & & & 2.9300 & \\
\hline Goodness & of fit LR Chi-square & 54.4500 & $* * *$ & & $48.5300 *$ & \\
\hline Log likelil & lood & -107.936 & & & -109.947 & \\
\hline Pseudo R & & 0.2014 & & & 0.1808 & \\
\hline Predicted & probability of participation & 0.4670 & & & 0.5308 & \\
\hline Observed & probability of participation & 0.5026 & & & 0.5258 & \\
\hline Number $\mathrm{c}$ & f observations & 195 & & & 194 & \\
\hline
\end{tabular}

\subsection{Probit Results}

The probit results indicate interesting systematic differences between participating households and their non-participating but eligible counterparts, and between the program districts (Table 2). In Chipata, widow-headed households were significantly more likely to be in the program if they were also female-headed. In Kazungula, widowhood was a significant determinant of 
participation, regardless of the sex of the household head and whether or not the household hosts orphans.

The age of the household head was significant only in Chipata. In that district, the effect of age was negative at the lower end of the age distribution and positive towards the upper end. This means that, even among the eligible households, child-headed and elderly-headed households had the highest chances of being included in the scheme, which is perfectly consistent with expectations. Household composition was a factor only in Kazungula, where various sub-categories of active age groups were inversely and significantly related to the probability of participation.

However, not all the results were consistent with expectations. In Kazungula, for example, households whose heads were 61 years or older were 39 percent less likely to be in the program than households that had younger heads. Also, households closest to main roads, schools and health posts were more likely to be in the program. It should also be noted that these results do not constitute an assessment of targeting effectiveness. As earlier stated, our sample was drawn from the program participants (i.e. the 10 percent most incapacitated of the ultra poor) as well as from those that had qualified to be in the program but were left out only because of the 10 percent ceiling. Thus, the probit models represent only the selection process from among the eligible households. The correct comparison group for a targeting evaluation is all households other than the participants.

\subsection{Impact on Consumption Expenditure}

The impact of the SCTs on consumption expenditure was unambiguously positive and statistically significant in both schemes, accounting for 57-85 percent of the beneficiary households' per capita consumption levels (Table 3). In Kazungula, the poorer of the two study districts, the impact was more than one-and-a-half times as much as in Chipata. This is not surprising as Kazungula had the most vulnerable target population. It appears that pre-intervention consumption levels may have been so low that the SCT intervention made a big difference. SCTs were especially effective in raising non-food consumption expenditure, accounting for 80-113 percent of the beneficiary households' per capita non-food consumption expenditure. In contrast, the impact on per capita food expenditure was significant only in Kazungula.

Table 3. Propensity score matching estimates of impact of the SCT pilot schemes on per capita consumption expenditure

\begin{tabular}{|l|c|c|}
\hline \multirow{2}{*}{ Outcome variable } & \multicolumn{2}{|c|}{ District } \\
\cline { 2 - 3 } & Chipata & Kazungula \\
\hline Natural log of per capita expenditure & $0.570^{* * *}$ & $0.854^{* * *}$ \\
\hline Natural log of per capita food expenditure & -0.030 & $0.399 * *$ \\
\hline Natural log of per capita non-food expenditure & $0.802 * * *$ & $1.132 * * *$ \\
\hline
\end{tabular}

Level of significance: $*=10$ percent, $* *=5$ percent, $* * *=1$ percent 
Table 4 presents impact estimates disaggregated by the households' asset wealth status (see Equation 3). The results indicate that the effect of asset-wealth on the relationship between SCTs and per capita consumption expenditure was significant only in the urban scheme of Chipata. By participating in the program, asset-poor households increased their food and non-food expenditure by 83 percent and 23 percent, respectively, more than they would have had they been less poor.

In general, wealth disparities tend to be greater in urban areas than in rural areas. That is, urban areas are expected to exhibit larger absolute differences between asset-poor and less poor households than rural areas. Therefore, it is not surprising that Chipata was the only one of the two schemes that exhibited significantly larger program effects among the poor than among the relatively less poor households. In this district, poorer beneficiary households were able to extract 23 percent more non-food program benefits than their relatively less poor counterparts.

Table 4. Heterogeneous impact of the SCT pilot schemes on consumption expenditure

\begin{tabular}{|c|c|c|}
\hline \multirow{2}{*}{ Outcome variable $^{a}$} & \multicolumn{2}{|c|}{ District } \\
\cline { 2 - 3 } & Chipata & Kazungula \\
\hline Total expenditure among less poor households & $0.504^{* * *}$ & $0.800^{* * *}$ \\
\hline Additional impact on total expenditure for poor households & 0.159 & 0.126 \\
\hline Food expenditure among less poor households & -0.377 & $0.387^{* *}$ \\
\hline Additional impact on food expenditure for poor households & $0.827^{* *}$ & 0.476 \\
\hline Non-food expenditure among less poor households & $0.706^{* *}$ & $1.052^{* *}$ \\
\hline Additional impact on non-food expenditure for poor households & $0.232^{*}$ & 0.192 \\
\hline
\end{tabular}

Level of significance: $*=10$ percent, $* *=5$ percent, $* * *=1$ percent

${ }^{a}$ Measured as natural logarithms of per capita values

\section{Summary and Conclusions}

This paper reports the relative impact of two spatially separated SCT schemes with design variations in Zambia. Descriptive results indicate that the SCT target households are truly incapacitated and highly vulnerable. Kazungula, the rural scheme, had as expected the poorest target group with household incomes just about a third of the levels observed in Chipata and almost half the daily number of meals taken by children. Impact results suggest that the SCT schemes are achieving their primary objective of improving immediate welfare, as indicated by their consistently positive impacts on per capita consumption expenditure. The greatest consumption effects were observed in Kazungula district, where the vulnerability levels were highest.

In conclusion, SCTs are an effective basic social protection tool in Zambia. However, expectations about their impact need to be tempered by program design and initial conditions. The significant wealth effects in Chipata seem to suggest that the program is meeting its primary objective of influencing the lives of the poorest. The greater aggregate consumption effects of the rural SCT scheme also seem to confirm, as expected, that eligible households in remote areas have lower welfare levels to start with. The lack of significant wealth effects in 
Kazungula further suggests that the differences in poverty between the poor and the relatively less poor are less apparent in the rural areas. Future planning of similar interventions needs to take into account the implication of heterogeneity in impact when considering design, location and target groups.

\section{Acknowledgements}

This work was supported by the World Bank, the UK Department for International Development (DfID), the German Technical Assistance (GTZ), the United Nations Children Fund (UNICEF), and CARE International. CARE International collected the data used in this study. The authors would also like to thank Ric Goodman, Kelley Toole, Charlotte Harland, Sheila Nkunika, Melissa Gonzales-Brenes, Sebastian Martinez, Mirey Ovadiya, Caglayan Isik, Stuart Kenward, Stephen Devereux, and Ricardo Sabates for their suggestions and comments on the initial drafts of the project report, on which this paper is based. However, the views expressed herein do not necessarily represent the official positions of any of these organizations and/or individuals. All errors in interpretation are the authors' own.

\section{References}

Becker, S. O., \& Ichino, A. (2002). Estimation of Average Treatment Effects based on $\begin{array}{lllll}\text { Propensity Scores. } & \text { Stata } & \text { Journal, } & 2, & 358-77 .\end{array}$ http://www.stata-journal.com/sjpdf.html?articlenum= st0026.

Caliendo, M., \& Kopeinig, S. (2008). Some Practical Guidance for the Implementation of Propensity Score Matching. Journal of Economic Surveys, 22, 31-72. http:dx.doi.org/10.1111/j.1467-6419.2007.00527.x

Cameron, C. A., \& Trivedi, P. K. (2005). Microeconometrics: Methods and Applications. Cambridge: Cambridge University Press.

Daidone, S., Davis, B., Dewbre, J., Gonzalez-Flores, M., Handa, S., Seidenfeld, D., \& Tembo, G. (2013). Out-of-Silo Effects of Social Cash Transfers: The Impact on Livelihoods and Economic Activities of the Child Grant Programme in Zambia. Paper submitted for presentation at the Oxford CSAE conference, Oxford, UK.

Filmer, D., \& Pritchett, L. H. (2001). "Estimating Wealth Effects without Expenditure Data or Tears: An Application to Educational Enrollments of India." Demography, 38(1), 115-132 .http:dx.doi.org/10.1353/dem.2001.0003

Gertler, P., Martinez, S., \& M. Rubio-Codina. (2006). Investing Cash Transfers to Raise Long-Term Living Standards. Policy Research Working Paper 3994, Impact Evaluation Series Number 6, Washington DC: The World Bank. http://ssrn.com/abstract=926443

Handa, S., Peterman, A., Seidenfeld, D., \& Tembo, G. (2013a). Income shocks and maternal health: Evidence from a national randomized social cash transfer program in Zambia. Unpublished manuscript.

Handa, S., Seidenfeld, D., \& Tembo, G. (2012). The Impact of a Large Scale Poverty Targeted Cash Transfer Program on Time Preference. Unpublished manuscript. 


\section{Macrothink}

Business and Economic Research ISSN 2162-4860 2014, Vol. 4, No. 1

Handa, S., Seidenfeld, D., Tembo, G., Prencipe, L., \& Peterman, A. (2013b). Zambia's Child Grant Program: 24-Month Impact Report. Washington DC, USA: American Institutes for Research (AIR).

Hirano, K., Imbens, G. W., \& Ridder, G. (2003). Efficient Estimation of Average Treatment Effects using the Estimated Propensity Score. Research Paper Number C02-13, USC Center for Law, Economics and Organization, University of Southern California Law School, Los Angeles, California.

Jalan, J., \& Ravallion, M. (2003). Estimating the Benefit Incidence of an Antipoverty Program by Propensity Score Matching. Journal of Business and Economic Statistics, 21, 19-30. http:dx.doi.org/10.1198/073500102288618720

Leuven, E., \& Sianesi, B. (2003). PSMATCH2: Stata Module to Perform full Mahalanobis and Propensity Score Matching, Common Support Graphing, and Covariate Imbalance Testing. http://ideas.repec.org/c/boc/bocode/s432001.html.

RHVP (Regional Hunger and Vulnerability Programme). (2007). Social Cash Transfers, Zambia. Regional Evidence Building Agenda (REBA) Case Study Brief Number 2. Johannesburg, RSA: RHVP. www.wahenga.net.

Rosenbaum, P., \& Rubin, D. (1985). Constructing a Control Group using Multivariate Matched Sampling Methods that Incorporate the Propensity Score. American Statistician, 39, 33-38. http://dx.doi.org/10.1080/00031305.1985.10479383

Seidenfeld, D., Handa, S., Prencipe, L., Huang, C., Tembo, G., \& Sherman, D. (2011). Results of the Three Year Impact Evaluation of Zambia's Cash Transfer Program in Monze District. Washington DC, USA: American Institutes for Research.

StataCorp. (2008). Stata Statistical Software: Release 10. College Station, TX: StataCorp LP.

Tembo, G., Freeland, N., Chimai, B., \& Schuring, E. (2014). Social Cash Transfers and Household Welfare: Evidence from Zambia's Oldest Scheme. Applied Economics and Finance 1(1), 13-26. http://dx.doi.org/10.11114/aef.v1i1.354

Tembo, G. \& Freeland, N. (2008). Impact of Social Cash Transfers on Household Welfare, Investment and Education. Lusaka, Zambia: Palm Associates Limited/MASDAR International Consultants.

\section{Copyright Disclaimer}

Copyright reserved by the author(s).

This article is an open-access article distributed under the terms and conditions of the Creative Commons Attribution license (http://creativecommons.org/licenses/by/3.0/). 